\title{
Pensar y educar \\ en el amor y la sexualidad \\ a los adolescentes
}

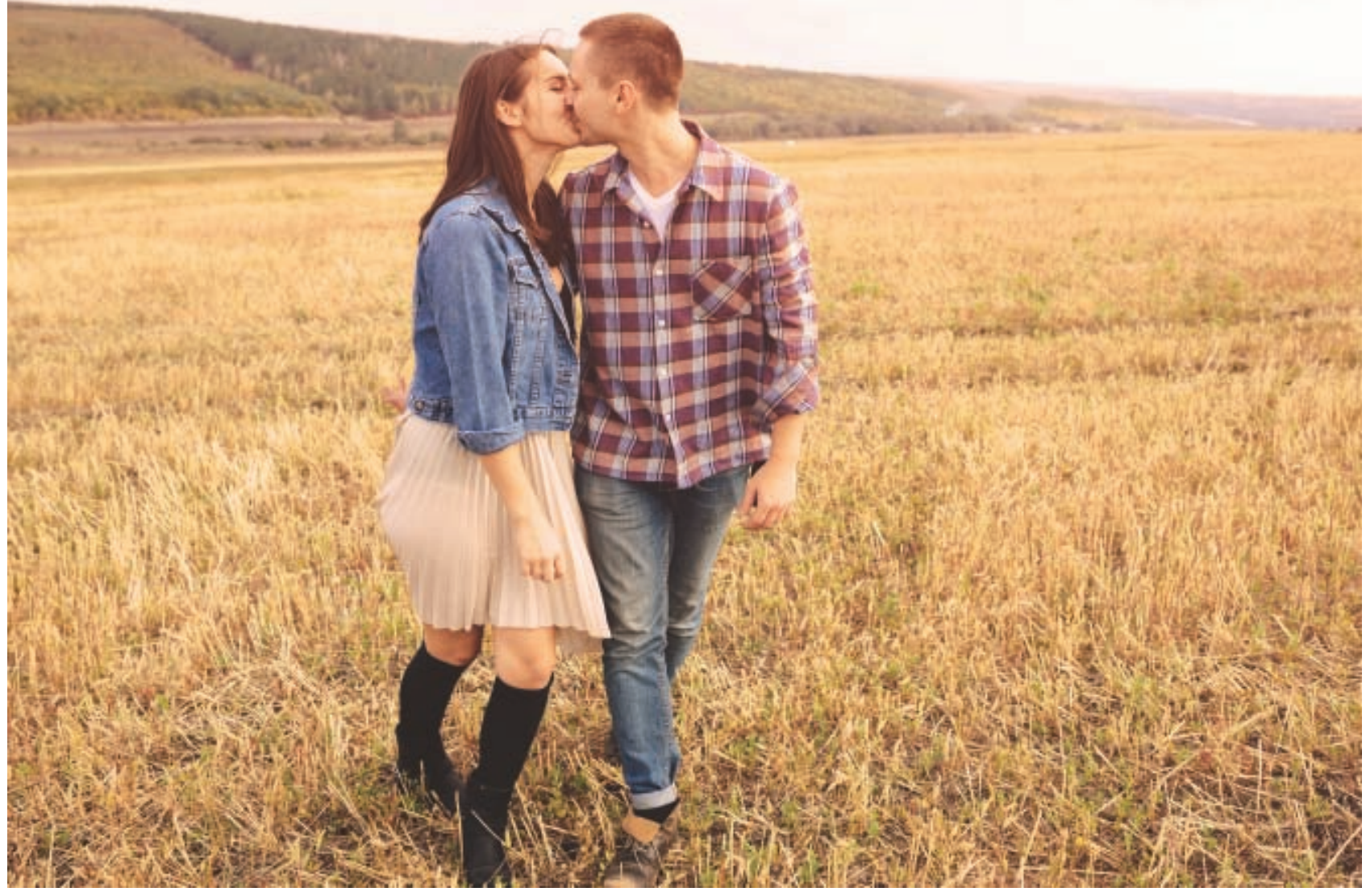

El amor y la sexualidad constituyen dos asignaturas pendientes en el desarrollo y madurez adolescente que requieren de un especial cuidado en su formación, diálogo y expresión. Padres y educadores

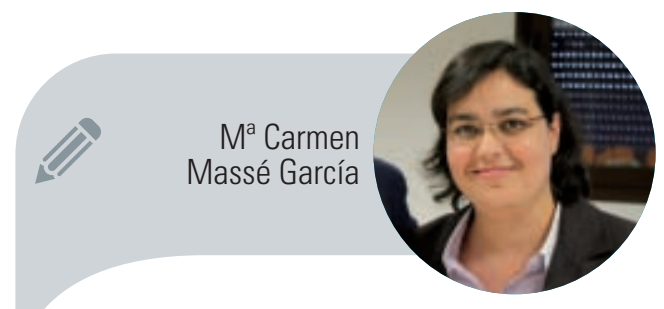

Profesora de la Universidad Pontificia Comillas mcmasse@comillas.edu debemos cuidar la semántica, la sintaxis y la gramática de este maravilloso lenguaje afectivo-sexual para acompañarlos en este camino. 
Somos cuerpo, somos seres sexuados. Pero, sobre todo, somos seres creados para amar. Ante esta más que evidente realidad, sólo tenemos una forma de conjugar sanamente ambas afirmaciones, en su ser biológico y en su ser afectivo y oblativo: la expresión sexual de un amor que demanda un proyecto.

No trataré en estas páginas de elaborar un complejo tratado sobre desarrollo afectivo sexual, ni tampoco de ofrecer un detallado itinerario formativo desde los primeros años de escolarización hasta la juventud en materia de sexualidad. Simplemente intentaré acercarme a la realidad que, desde mi experiencia docente, más nos preocupa a educadores, padres y también a los chicos: cómo educar y enseñar a pensar libre y responsablemente el amor y la sexualidad en los difíciles años de la adolescencia, cuando nuestra biología ya está preparada para ejercitarse en toda su plenitud, pero psicoafectivamente aún nos queda mucho camino por recorrer.

El papel de la bioética en las aulas no puede eludir esta fascinante dimensión de la vida que debe ser cuidada desde la libertad y la responsabilidad. La experiencia de cuerpo sexuado de nuestros adolescentes es, sin duda, un ámbito de extrema vulnerabilidad que demanda nuestra atención. $Y$, al mismo tiempo, nuestros chicos y chicas tienen en sus poderosas manos la posibilidad de dañar indeleblemente la dignidad de un compañero/a, amigo/a y, aún más, de llamar a la vida a un nuevo ser humano que no será fruto de un amor creador, de una decisión libre y responsable, de una voluntad de amor y acogida incondicional.

Para comenzar nuestro itinerario es bueno conocer, de primera mano, la realidad que tenemos frente a nosotros, quiénes son los adolescentes que se sientan en nuestras aulas.

\section{La realidad en nuestras aulas}

Los últimos datos publicados por el INE (2004) nos muestran que la edad media de inicio de relaciones sexuales en nuestro país es de 18,1 años para los chicos y de 19,1 años para las chicas. Otros estudios adelantan las edades a los 15,3 y 15,9 años, respectivamente. En todo caso, sirva el dato en el que coinciden la mayoría de los expertos, según el cual el $28,3 \%$ de los chicos de entre 15 y 17 años ya han tenido relaciones sexuales siendo más de la mitad los que se han iniciado antes de los 19 años (54,3\%). Y, de todos ellos, el 70\% dicen utilizar algún método anticonceptivo.

Si nos preguntamos por las relaciones homosexuales, en nuestro país el $6 \%$ de los chicos las mantienen (y el $2 \%$ dicen tenerlas tanto con chicos como con chicas), mientras que entre las chicas el
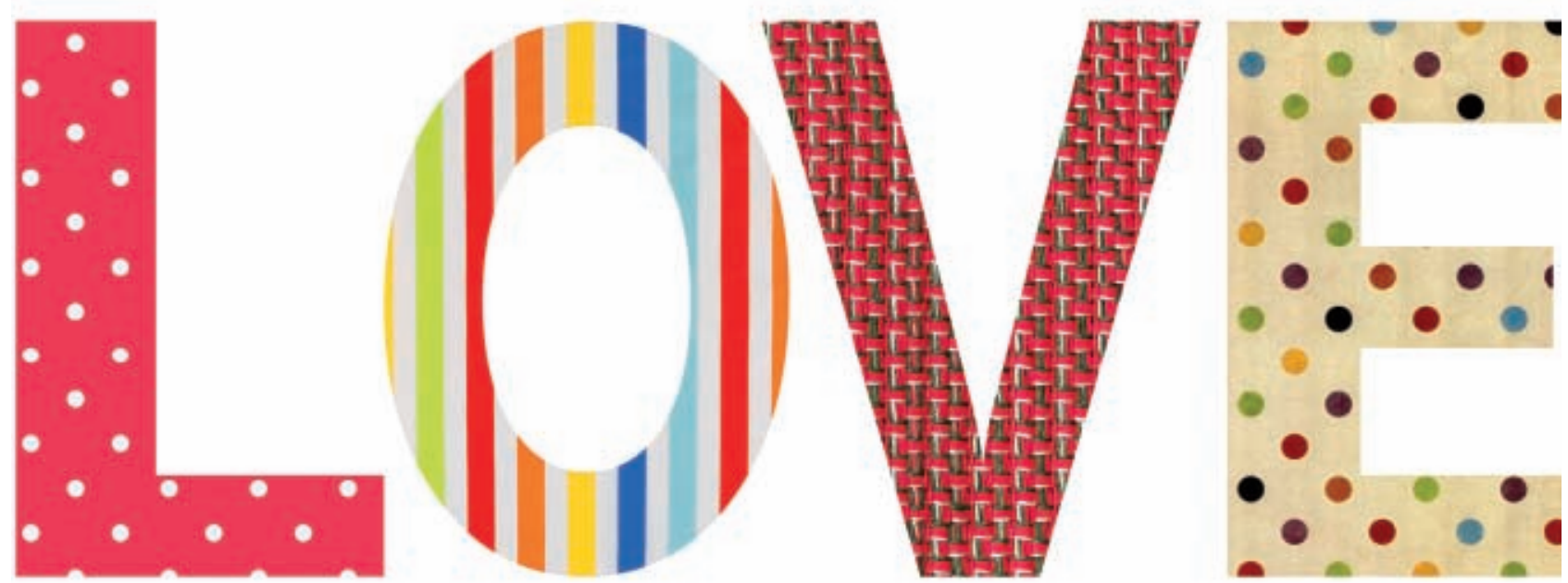


\section{Conocer la realidad en España}

porcentaje se reduce a la mitad, el 3\%. Por tener una referencia, hemos de saber que en la población adulta las cifras no son muy diversas, el 3-5\% de los varones y el $2-3 \%$ de las mujeres. Es posible que la inmadurez, la indefinición y las muchas influencias culturales y sociales sufridas en la adolescencia hagan que sean algo superiores, en un intento de experimentar y buscar una forma de placer al que no están dispuestos a renunciar de entrada.

Finalmente, las prácticas autoeróticas son claramente una experiencia masculina en la adolescencia, presentes en el $70 \%$ de los chicos de Educación Secundaria de nuestras escuelas, mientras que entre las chicas la cifra se invierte, apenas el $30 \%$.

\section{Educar en el amor y la sexualidad, voces necesarias y palabras ineludibles}

Si nos disponemos a educar a los adolescentes en la difícil tarea de amar y expresarlo sexuadamente, es importante conocer cuáles son las voces que ellos escuchan para adquirir los conocimientos que creen necesitar. Quizás podemos caer en la tentación de pensar que toda la información que tienen es la que les vayamos a dar y, ciertamente, en la era de las comunicaciones y en el mundo de las TICs, que sin duda han conquistado antes que nosotros, quizás hemos llegado tarde. Acerquémonos a la realidad a través del gráfico 1.

Es importante reconocer la relevancia que nuestros adolescentes dan a la formación que obtienen en los centros educativos, siendo el ámbito donde más información relevante obtienen sobre su sexualidad. La mayoría de sus fuentes de información para estas cuestiones la obtienen de la escuela, los amigos e Internet, con algunas diferencias significativas entre chicos y chicas, como la presencia en las chicas del diálogo con sus padres (sumaría un 28,3\% las que obtienen información de sus madres y sus padres) y la relevancia en los chicos de la información obtenida viendo películas de contenido pornográfico (un 17,2\%). y La edad media de inicio de relaciones sexuales: 18,1 años los chicos y de 19,1 años las chicas (INE 2004). Muchos estudios lo adelantan: 15,3 años los chicos y 15,9 años las chicas.

$\searrow$ Relaciones sexuales completas:

, $28,3 \%$ de los chicos de entre 15 y 17 años.

, $54,3 \%$ antes de los 19 años (54,3\%).

, El $70 \%$ dicen utilizar algún método anticonceptivo.

$\searrow$ Relaciones homosexuales: $6 \%$ de chicos y $3 \%$ de chicas.

У Prácticas autoeróticas: $70 \%$ de chicos y $30 \%$ de chicas.

\section{Gráfico 1. Cómo obtuvo información sobre sexualidad y cuidados} de la salud sexual. Porcentajes.

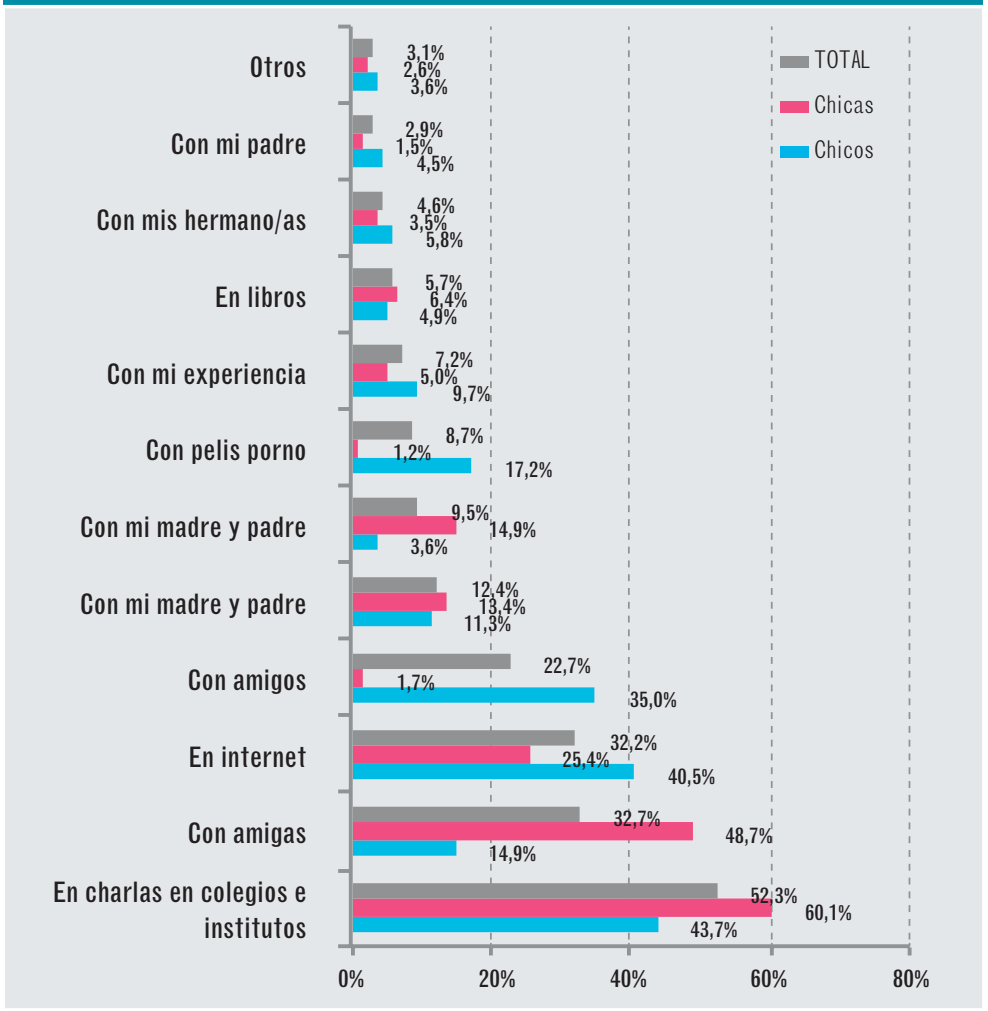

Constatando sus fuentes de información hemos de tener en cuenta qué voces son inexcusables escuchar en este diálogo de vida y qué palabras no pueden estar ausentes en su formación para la vida y el amor:

7 La voz de las ciencias biosanitarias, cuyo deseo (como el nuestro) no es otro que velar por su salud. Es importante que conozcan las infinitas posibilidades que su anatomía y fisiología les ofrecen para expresarse, gozar y también, no debemos olvidarlo, para enfermar y abrir heridas del corazón para las que no sirven antibióticos ni 


\section{Voces que deben escuchar}

1. Para estar sanos: las ciencias biosanitarias. Su anatomía y fisiología, sus goces y sus riesgos.

2. Para ser felices: la fe en grandes tradiciones religiosas, la Ética, la Filosofía. Dar sentido a su cuerpo y su sexualidad, haciendo de ellas un proyecto de vida que merezca la pena ser vivida.

3. Para aprender a caminar juntos: la voz de su pareja. Chicos y chicas adolescentes viven en dos cosmovisiones muy diferentes y que dan por hecho que es compartida.

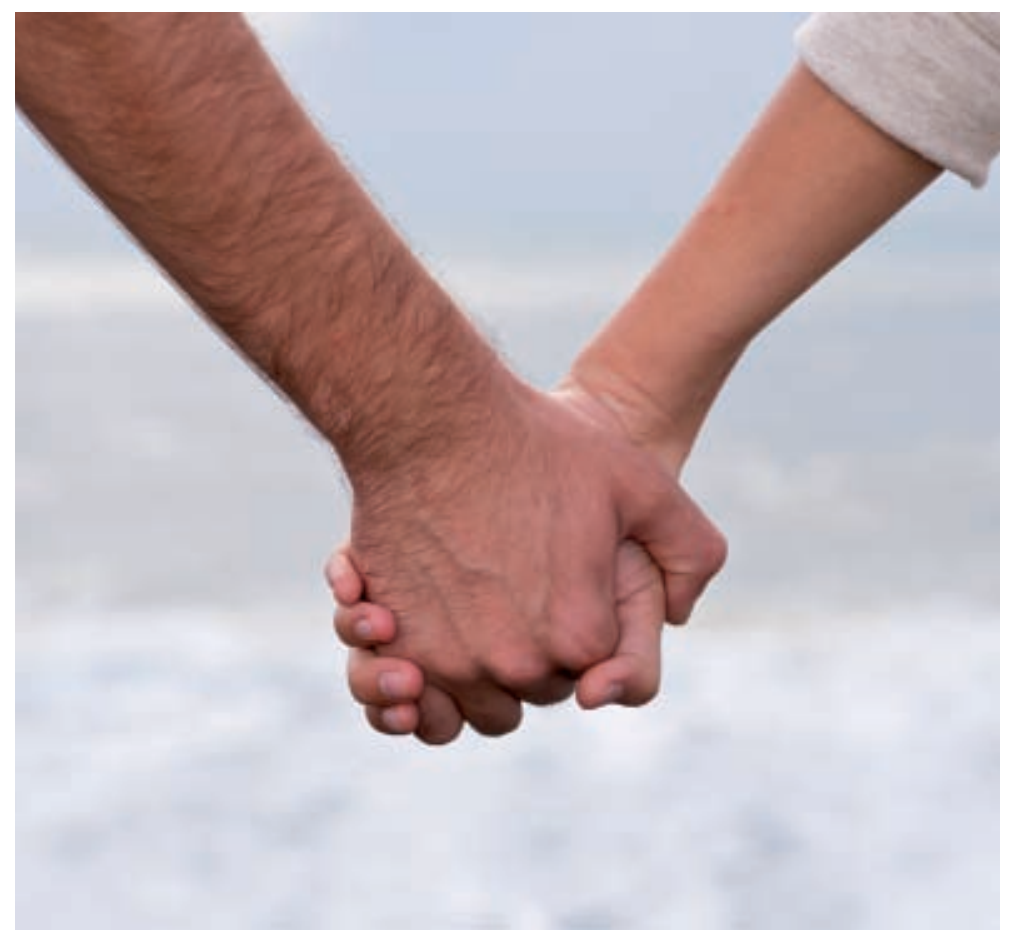

quirófanos. En este sentido tenemos que ayudarles a conocer las enfermedades de transmisión sexual y el modo de prevenirlas; a romper los mitos de fecundidad y de cómo evitarla con información completa y veraz sobre fisiología de la reproducción y métodos anticonceptivos; a distinguir el verdadero amor que te hace libre y responsable de la enfermiza posesión que conduce a la violencia y a la humillación, que perdurarán en el alma de nuestros chicos (y sobre todo en el de nuestras chicas) por mucho tiempo.

$\boldsymbol{\lambda}$ La voz de quienes no sólo quieren ver a nuestros chicos sanos sino también felices, dando sentido a su cuerpo y su sexualidad, haciendo de ellas un proyecto de vida que merezca la pena ser vivida. Es ahí donde podemos situar la voz de la fe en las familias y en los colegios confesionales, es la voz de la
Iglesia o la voz de tantas otras tradiciones religiosas presentes en nuestra geografía y que nos anteceden en siglos de experiencia en su propuesta de vida y amor. Es la voz también de la ética y la filosofía, la voz de tantos hombres y mujeres que han pensado con hondura estas cuestiones.

त Y una voz que nunca deben eludir es la voz de la pareja. Sí, ese tú adolescente, probablemente desconocido en tantos rincones que resultan inescrutables para chicos y chicas, que tiene su propia experiencia y concepción del cuerpo, del amor, de la vida, del placer, de la familia, de los sueños..., de la pareja. Chicos y chicas adolescentes viven en dos cosmovisiones muy diferentes, raramente coincidentes, y que tienden a pensar respectivamente que es compartida. En mi experiencia como educadora en estas cuestiones, he de reconocer que sistemáticamente olvidan hablar de amor y sexualidad con sus propias parejas. Pa rece que también lo olvidan algunos estudios como el que he presentado anteriormente.

Y todas estas voces tendrán que enseñarles a conjugar determinados verbos con sujetos y predicados que están despertando en sus vidas. Las primeras palabras que tenemos que enseñar a pronunciar para comenzar a construir son dos: "sí"y "no". Reconocer nuestras necesidades y límites, saberlos expresar y hacer valer son tareas que, en ocasiones, pueden resultarles ciertamente difíciles a nuestros adolescentes cuando hablamos de relaciones de pareja.

Las siguientes palabras que han que aprender a pronunciar, con temor y temblor, son aquellas grandes palabras que forman parte de la maduración humana: vida, amor, dignidad, respeto, sentido, responsabilidad, entrega, generosidad. Es fundamental que en nuestros hogares y escuelas los chicos se vean acompañados y respetados en este largo camino que apenas comienzan a emprender y que les habrá de conducir a un proyecto de vida que sólo se entiende con otros. 
Y, finalmente, todas estas palabras tienen que aprender a conjugarse en singular para que, tras un camino de maduración juntos, puedan llegar a conjugarse en plural de tal forma que sabiendo articular sanamente "quiero", "deseo", "espero", "confío", "entrego"..., pueda llegar a conocer la hondura de pronunciar con un tú "queremos", "esperamos", "deseamos", "conflamos", "nos entregamos".

\section{Claves para ser escuchados}

Grandes palabras, verbos arriesgados, conceptos abstractos. Hablar a los adolescentes de amor y sexualidad es un trabajo de artesanía que requiere destreza e inflnito cuidado para no romper en segundos el esfuerzo de mucho tiempo. Quisiera, a continuación, ofrecer algunas claves que pueden facilitar la comprensión y el diálogo, la acogida y la escucha de los adolescentes en este ámbito en el que no todo lo que van a oír es aquello que les gustaría escuchar.

1. El amor de pareja es un amor erótico que se expresa a través de un lenguaje. Y como todo lenguaje, necesitamos aprender con paciencia y constancia, su gramática y vocabulario. Un lenguaje que tiene tantas formas de expresión como personas y parejas, abierto a la creatividad y la imaginación, que cuenta con palabras y gestos, presencias y ausencias, entregas y renuncias. Cuando aprendemos un idioma, no podemos esperar convertirnos en experimentados traductores de literatura el primer día, sino que debemos ejercitarnos de forma gradual. En este sentido, no es difícil entender el significado del monólogo solitario de quien reduce la expresión sexual a las prácticas autoeróticas.

2. El valor fundamental de todo lenguaje es la verdad. La verdad en el amor significa que no podemos expresar del mismo modo "me gustas" que "te quiero a mi lado para siempre", por ejemplo. Expresar lo que ciertamente no quieres decir es, sencillamente, mentir, y las mentiras hieren. No es posible construir un proyecto, otorgar un sentido, basándonos en la mentira.
1. El amor de pareja es un amor erótico que se expresa a través de un Ienguaje.

2. El valor fundamental de todo lenguaje es la verdad. Expresar lo que ciertamente no quieres decir es mentir, y las mentiras hieren.

3. La pareja es un tú como yo, un sujeto, y no un objeto más de placer, de diversión y entretenimiento.

4. No rompamos lo más sagrado del otro: su dignidad.

3. La pareja es un "tú como yo", un sujeto, y no un objeto más de placer, de diversión y entretenimiento como puede serlo la Play Station, el ordenador o la televisión. Tanto mi pareja como yo somos mucho más que un cuerpo, que una parte de mi cuerpo a disposición del otro.

4. No rompamos lo más sagrado del otro: su dignidad. Construir una relación desde el respeto, el diálogo y la verdad es lo que nos llevará a construirnos como sujetos con un proyecto de sentido, como parejas y familias que formarán parte esencial de nuestra sociedad.

Son claves para formar e informar, claves de contenido que nuestros adolescentes comprenden perfectamente, alcanzan a ver el sentido y les llevan a intuir las consecuencias para sus vidas. Padres y educadores deseamos, no sólo la salud sino, sobre todo, la felicidad de los chicos y chicas que tenemos en nuestras manos. En esta sociedad de consumo son demasiadas las agresiones a su frágil e incipiente libertad y responsabilidad. Agresiones que llegan por cauces que ya no podemos (ni debemos) controlar a estas edades. La privacidad de los adolescentes, sus relaciones, sus redes sociales y su tiempo son terreno inexplorado e inexplorable, a riesgo de perder toda confianza que hayamos conseguido ganar en años de relación sincera.

Es por ello que, no menos importante que los contenidos y claves, debemos cuidar las formas y actitudes con las que entrar en diálogo sincero y fecundo con quienes apenas están estrenando un cuerpo que les desborda y en una voluntad que les supera.

En primer lugar, hemos de tener en cuenta que nosotros, padres o educadores, somos seres sexuados y que así nos 


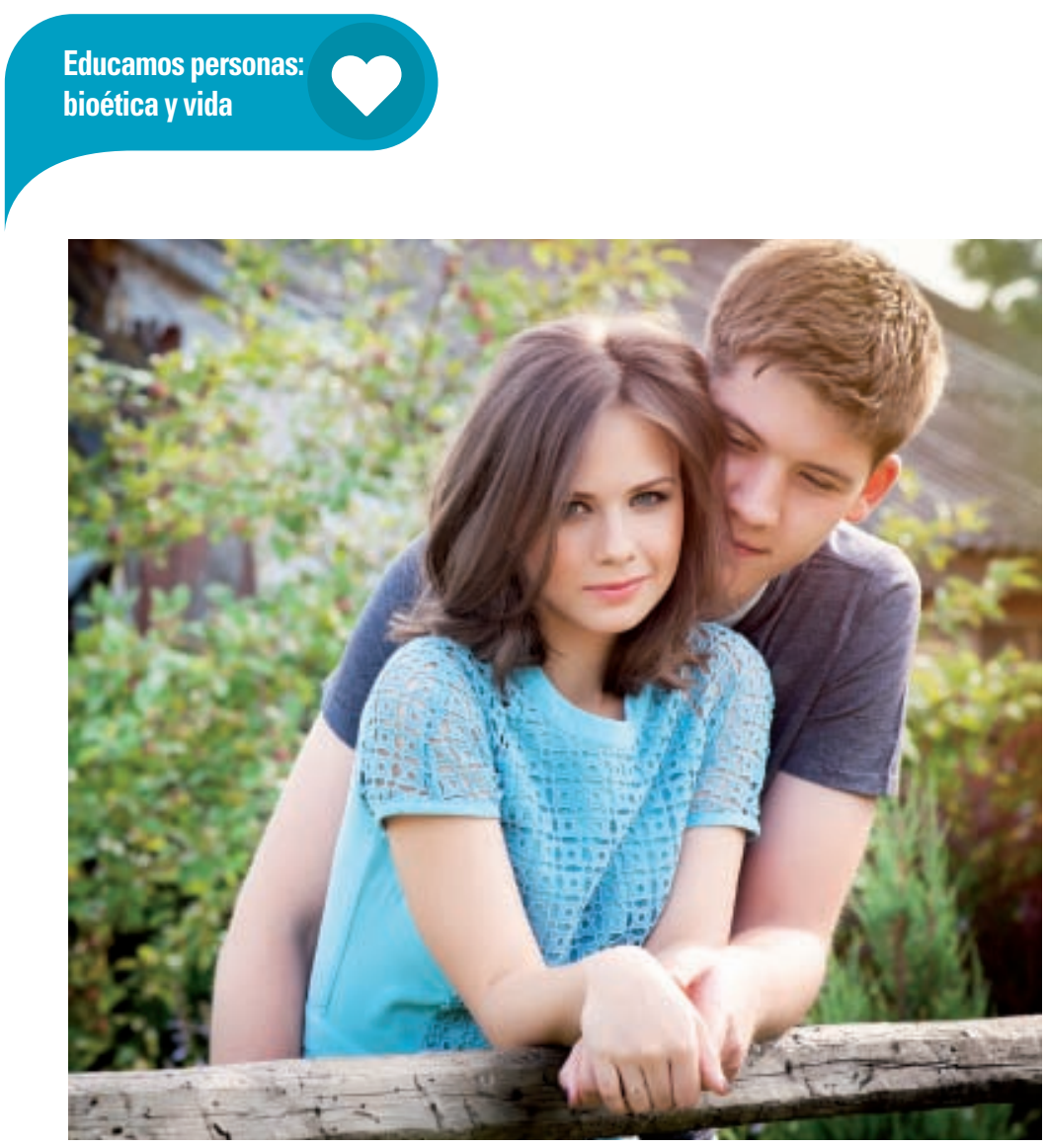

relacionamos y expresamos. La labor educativa más importante es la que ejercemos con nuestra vida y ejemplo. Es lo primero y quizás lo único que van a ver y reconocer los chicos, será la prueba de coherencia de lo que queramos decir y transmitir: cómo nos relacionamos con personas del mismo o de diferente sexo u orientación sexual, cómo construimos la vida de pareja o la familia, nuestra capacidad de entrega, de generosidad, de sacrificio en pareja o en familia, nuestro modo de cuidar y valorar el cuerpo. Los modelos de identificación son más poderosos en su formación que las palabras o las imágenes, vengan de una charla formativa o de una película de contenidos pornográficos.

En segundo lugar, hemos de transmitir un profundo y sincero respeto y valoración de la propia realidad que experimenta el adolescente. Su forma de ver la vida y el amor, de comprender la sexualidad y el cuerpo, sus problemas, dudas, relaciones fallidas y fracasos son reales y sinceros y merecen toda nuestra atención.

Y, en tercer lugar, debemos abandonar ciertas actitudes que alejan definitivamente al adolescente de cualquier propuesta por excelente que nos parezca: el recurso al miedo (a contraer enfermedades, al embarazo, al rechazo por los pares o por los adultos, etc.), pues un adolescente se siente más todopoderoso que vulnerable y su amor (o enamoramiento) todo lo vence; los moralismos, las normas no integradas, las reglas no entendidas, pues se siente más libre que cualquier adulto; los voluntarismos que lo fían todo a la capacidad ilimitada de control de una voluntad que está muy lejos de ser conocida, reconocida $y$, mucho menos, dominada; y, finalmente, tampoco les ayuda un cómodo liberalismo en el que "todo vale" si se hace con amor o si hay buena intención, pues necesitan adultos y no "colegas" con los que puedan confrontarse y establecer límites sanos.

En definitiva, en nuestros hogares y centros educativos tenemos la oportunidad de preparar a nuestros chicos y chicas para aprender, acoger, cuidar y construir los dos grandes pilares sobre los que sin duda se construye nuestra sociedad: la vida y el amor. Son los pilares que también habrán de conformar sus propios proyectos vitales dándole sentido al presente, integrando el pasado y soñando un futuro esperanzador compartido. No hay libros de texto para ello, es entonces cuando nuestras vidas y nuestro amor deben tomar la palabra •

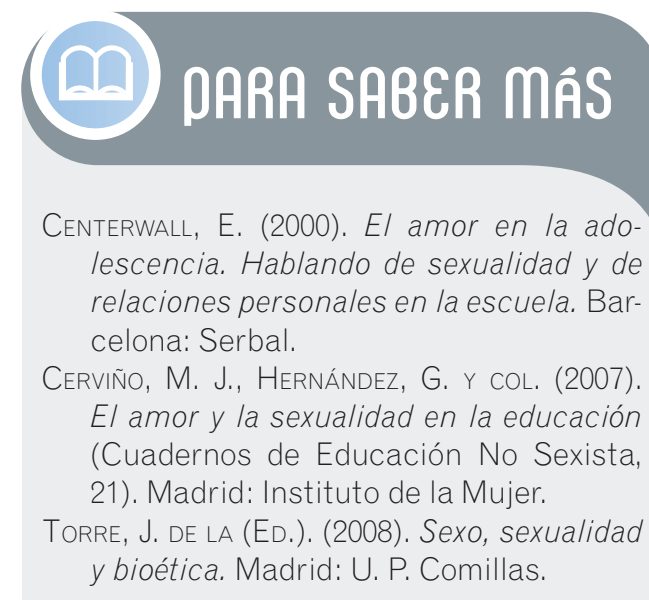

\section{HEMOS HABLADO DE
Educación sexual; afectividad; moral
sexual; salud sexual y reproductiva.}

Este artículo fue solicitado por PADRES y MAESTROS en diciembre de 2014, revisado y aceptado en mayo de 2015. 